\title{
Development of Intensive Care in Low-Resource Regions
}

\author{
Janat Tumukunde ${ }^{1} \cdot$ Cornelius Sendagire $^{1,2} \cdot$ Stephen Senyonjo Ttendo ${ }^{3}$ \\ Published online: 18 January 2019 \\ (C) Springer Science+Business Media, LLC, part of Springer Nature 2019
}

\begin{abstract}
Purpose of review Since their introduction almost a century ago, intensive care units have become an essential part of the health care system. Although the majority are found in the high-income countries, access to intensive care in the low-income countries has improved. The purpose of this review is to report on the current state of intensive care in resource-limited settings.

Recent Findings Lack of basic health care resources still poses a specific challenge to the development and sustainability of health care. In addition, adequate funding, human resource training, and equipment specific to the specialty of critical care pose an even larger setback to the development of critical care in low-resource-limited settings.

Summary Deaths potentially preventable with access to critical care as presented by data from the global disease burden analysis in 2004 are approximately $70 \%$ of all recorded deaths in low-income countries. This reflects the large burden of critical illness in low-income countries. Efforts to increase access to hospitals and intensive care for all critically ill patients should grow to match these needs.
\end{abstract}

Keywords Intensive care in low resource $\cdot$ Low-resource ICU capacity $\cdot$ ICU bed capacity $\cdot$ Cost of intensive care

\section{Introduction}

Since the early 1990 s, research has led to a change in practice within the intensive care units. Standardized protocols developed by international groups have been generated and generally accepted as guidelines to patient management, with room to adapt them to local needs. The current paradigm shift of care for critically ill patients to "less is more" approach where critically ill patients receive less aggressive care and minimum requirement of organ support has not only greatly improved outcomes but also the cost implications in terms of in-hospital stay [1-3] which blends in well with a low-resource setting.

This article is part of the Topical Collection on Global Health Anesthesia

Janat Tumukunde

janattumukunde@gmail.com

1 Anaesthesiologist, Department of Anaesthesia, College of Health Sciences, Makerere University, P.O. Box 7072, Kampala, Uganda

2 Anaesthesiologist Registrar, Department of Cardiac Anaesthesia and Critical Care, Uganda Heart Institute, P.O. Box 7051,

Kampala, Uganda

3 Anaesthesiologist, Department of Anaesthesia, Mbarara University of Science and Technology, P.O. Box 1410, Mbarara, Uganda
While intensive care has greatly advanced over the last six decades to provide the highest level of safe medical care and improve outcomes, there was a delay by more than a decade between the development of intensive care medicine in developed countries and low-income settings [4]. Intensive care medicine remains a novel field in this setting where primary health care is the most advocated aspect while care for the sickest of patients is relegated in terms of priorities for health care largely due to the supposed high-cost implications of the latter.

It is important to note that while the world focuses on improving access to health care, critical care is as important as surgery and anesthesia and is a valuable discipline of medicine which when developed, compliments and makes both surgery and anesthesia even safer.

The purpose of this review is to look at the available data on the different aspects of critical care in low-resource settings and present any advances and specific needs in this field.

It is important to note that there is generally a paucity of data on intensive care in low-resource regions.

\section{Burden of Critical Illness}

Adhikari et al. described three general approaches in trying to estimate the global burden of critical illness. First is 
to extrapolate from resource-rich countries epidemiology, second is to count every patient that is admitted into the intensive care unit, and the third is to assume that every death involved a critical illness at some stage [5]. The first two methods are likely to underestimate the burden due to the limited number of ICUs in low-resource settings and the third will most likely lead to an over estimation. The lack of reliable predictive scores makes the estimation of the burden critical illness difficult.

While the actual burden of critical illness in resourcelimited settings remains unmeasured, one can get an idea from the different papers written about disease outbreaks like Ebola [6], medical specialties like pediatrics [7, 8•], emergency medicine [9॰], cardiovascular disease [10], and the global disease burden [11]; all these without mentioning the fact that Sub Saharan Africa alone contributes $70 \%$ to the global deaths from HIV [12].

Therefore, critical illness is as real in developing countries as it is in developed countries.

\section{Cost-Effectiveness of Intensive Care}

Management of critically ill patients needs expensive equipment, drugs and procedures, and highly skilled personnel and yet the mortality remains high; between 8 and $33 \%$ across the world [13, 14]. Cost-effectiveness of setting up intensive care is an ongoing debate given that it is deemed expensive and yet primary health care is still a challenge in resource-limited settings. For perspective, it is estimated that the cost of the first day in ICU ranges between 1000 and 2000 USD depending on whether the patient is mechanically ventilated or not, with a total cost of 14 days in ICU estimated at 34,000 USD $[15,16 \bullet \cdot$. It is therefore not surprising that in low-resource settings, intensive care is considered costly and when compared to the recorded mortality, it makes the need for intensive care difficult to justify. Not many cost studies have been done in resource-poor settings, but one by Cubro et al. suggests that intensive care treatment is as cost-effective and compares favorably to interventions long considered cost-effective, such as HIV care, immunizations, and general primary health care [17••]. Interventions like close patient monitoring, timely antibiotic administration, and fluid resuscitation in intensive care do not need to be resource intensive and have been shown to affect overall mortality while refusal or delayed admission is associated with increased mortality [18]. The population in the developing world is relatively younger with less co-morbidities providing a great opportunity to show the benefit of critical care.
Intensive Care Unit Capacity and Resources

There is a paucity of data regarding the average number of ICU beds, both adult and pediatric. A systematic review of 15 low-income countries carried out in 2015 revealed a range of 0.1-1.7 beds per 100,000 persons with an annual admission rate of 401 patients while the developed countries have an overall of 33.6 ICU per 100,000 persons [19••, 20]. A more comprehensive database that reflects the ratio of ICU to hospital beds is needed.

Intensive care units often have to function with limited resources. Basic diagnostic and monitoring equipment is limited, not readily available, and often not maintained. Running water, electricity, oxygen, and basic medicines are erratic in supply. Solutions to some of these include use of alcohol hand gels, battery-operated devices, use of oxygen concentrators during oxygen shortages, safe reuse of certain consumables like ventilator circuits, and non-invasive blood pressure cuffs. Skills and techniques like bedside ultrasonography have been applied to circumvent the lack of mobile imaging and pulse oximetry monitoring is relied on heavily instead of regular blood gas sampling.

While there is a need and will to develop and improve critical care, there is a dire need of experts specifically trained in intensive care in the form of doctors and nurses. However, low wages drive majority of the trained personnel out of their centers and the few available personnel are overworked and come at a very high cost. A convenience sampling of 13 lowmiddle income country ICUs showed that $77 \%$ lacked trained staff and identified this as the most important barrier to the development of intensive care [8•, 21••, 22]. These factors double as reasons for the reduced number of ICU beds that is mentioned in the majority of the published literature. Other factors identified include the lack of supplies, coordination, infrastructure, and human resource [23].

\section{Current Intensive Care Practices}

Intensive care involves the provision of intensive specialized medical and nursing care alongside enhanced monitoring of critically ill patients. Multiple methods of physiological support are applied during transitional times of organ insufficiency.

There is an increased awareness of the fact that intensive care practices in low-resource-limited centers are largely influenced by data from developed countries whose population greatly differs from that in resource-limited settings. The lowincome population is young and free of chronic illnesses [9•] and with different disease patterns. Infectious diseases such as $\mathrm{HIV}$, tuberculosis, and malaria, malnutrition, and road traffic accidents are the main contributors to morbidity and mortality in low-resource regions, and as such will be the biggest 
contributors to ICU admissions. As a result, there has been a move to study our own population and tailor interventions to our needs, such as the recommendations for sepsis management in resource-limited centers [24].

\section{Conclusion}

While the burden of disease is noted to be large and the benefits of critical care recognized, the ICU capacity in resourcelimited settings remains largely undocumented and low. It is therefore important that efforts should be focused first on documenting the current capacity and second, on lobbying for both human resource training, retention to run the available units and develop standards of care for critically ill in lowresource settings.

\section{Compliance with Ethical Standards}

Conflict of Interest Janat Tumukunde, Cornelius Sendagire, and Stephen Senyonjo Ttendo declare that they have no conflict of interest.

Human and Animal Rights and Informed Consent This article does not contain any studies with human or animal subjects performed by any of the authors.

Publisher's Note Springer Nature remains neutral with regard to jurisdictional claims in published maps and institutional affiliations.

\section{References}

Papers of particular interest, published recently, have been highlighted as:

- Of importance

-• Of major importance

1. Marik PE. The cost of inappropriate care at the end of life: implications for an aging population. Am J Hosp Palliat Care. 2015;32(7):703-8

2. Siddharthan T, Karakousis PC, Checkley W. Empirical antifungal therapy in critically ill patients with sepsis: another case of less is more in the ICU. Jama. 2016;316(15):1549-50.

3. Gopalratnam K, Forde I, O'Connor J, Kaufman D. Less is more in the ICU: resuscitation, oxygenation and routine tests. Semin Respir Crit Care Med. 2016;37(1):23-33.

4. Berthelsen PG, Cronqvist M. The first intensive care unit in the world: Copenhagen 1953. Acta Anaesthesiol Scand. 2003;47(10): 1190-5.

5. Adhikari NKJ, Fowler RA, Bhagwanjee S, Rubenfeld GD. Critical care and the global burden of critical illness in adults. Lancet. 2010;376(9749):1339-46.

6. Murthy S. Ebola and provision of critical care. Lancet. 2015;385(9976):1392-3.
7. Tripathi S, Kaur H, Kashyap R, Dong Y, Gajic O, Murthy S. A survey on the resources and practices in pediatric critical care of resource-rich and resource-limited countries. J Intensive Care. 2015;3:40.

8. Slusher TM, et al. Pediatric critical care in resource-limited settings — overview and lessons learned. Front Pediatr. 2018;6(49) States the needs of setting up a PICU.

9. Obermeyer Z, et al. Emergency care in 59 low- and middle-income countries: a systematic review. Bull World Health Organ. 2015;93(8):577-586g Highlights the population characteristics that contribute to ICU population.

10. Bowry ADK, Lewey J, Dugani SB, Choudhry NK. The burden of cardiovascular disease in low- and middle-income countries: epidemiology and management. Can J Cardiol. 2015;31(9):1151-9.

11. Murray CJL, Lopez AD. Measuring the global burden of disease. $\mathrm{N}$ Engl J Med. 2013;369(5):448-57.

12. Gostin LO. Why rich countries should care about the world's least healthy people. Jama. 2007;298(1):89-92.

13. Williams TA, Dobb GJ, Finn JC, Webb SAR. Long-term survival from intensive care: a review. Intensive Care Med. 2005;31(10): 1306-15.

14. Siddiqui S. Mortality profile across our intensive care units: a 5year database report from a Singapore restructured hospital. Indian J Crit Care Med. 2015;19(12):726-7.

15. Dasta JF, McLaughlin TP, Mody SH, Piech CT. Daily cost of an intensive care unit day: the contribution of mechanical ventilation. Crit Care Med. 2005;33(6):1266-71.

16.• Gershengorn HB, Garland A, Gong MN. Patterns of daily costs differ for medical and surgical intensive care unit patients. Ann Am Thorac Soc. 2015;12(12):1831-6 Highlights the population characteristics that contribute to ICU population.

17.• Cubro H, et al. Cost effectiveness of intensive care in a low resource setting: a prospective cohort of medical critically ill patients. World J Crit Care Med. 2016;5(2):150-64 Identifies the fact that intensive care costs as much as primary health care and need not considered too expensive.

18. Robert R, Reignier J, Tournoux-Facon C, Boulain T, Lesieur O, Gissot V, et al. Refusal of intensive care unit admission due to a full unit: impact on mortality. Am J Respir Crit Care Med. 2012;185(10):1081-7.

19.• Murthy S, Leligdowicz A, Adhikari NKJ. Intensive care unit capacity in low-income countries: a systematic review. PLoS One. 2015;10(1):e0116949 The only paper that has estimated the intensive care capacity in low-resource settings.

20. Wallace DJ, Angus DC, Seymour CW, Barnato AE, Kahn JM. Critical care bed growth in the United States. A comparison of regional and national trends. Am J Respir Crit Care Med. 2015;191(4):410-6.

$21 . \bullet$ Haniffa R, et al. Improving ICU services in resource-limited settings: perceptions of ICU workers from low-middle-, and highincome countries. J Crit Care. 2018;44:352-6 Practitioners from resource-limited settings clearly state what their needs and thoughts are regarding intensive care.

22. Vukoja M, et al. A survey on critical care resources and practices in low- and middle-income countries. Glob Heart. 2014;9(3):337342.e5.

23. Basnet S, Adhikari N, Koirala J. Challenges in setting up pediatric and neonatal intensive care units in a resource-limited country. Pediatrics. 2011;128(4):e986-92.

24. Dunser MW, et al. Recommendations for sepsis management in resource-limited settings. Intensive Care Med. 2012;38(4):557-74. 